\title{
Introduction of a new testing method (horizontal sorption) for the in-situ analysis of water absorption by porous stone surfaces and effect of surface treatments
}

\author{
Péter Juhász*, Katalin Kopecskó \\ Department of Construction Materials and Engineering Geology, Budapest University of Technology and \\ Economics, Budapest, Hungary
}

\begin{abstract}
The aim of this paper is to introduce the horizontal sorption technique and to demonstrate its applicability for the observation of porous materials and effect of surface treatments. The horizontal sorption testing method is a new technique, which was developed to facilitate the in-situ assessment of water absorption properties of porous materials. This new technique has some advantages compared to the already existing in-situ testing methods (Karsten pipe method, contact sponge method). It is easy to use, requires no supplementary electric devices, and tight attachment of the measuring tool onto the surface is not necessary. Moreover, the absorption of the water can be easily initiated and then documented. In the present paper several different ways of application of the technique are shown. The testing method was proven to be appropriate for the evaluation of the rate of water absorption, for determination of the sedimentary fabric of the rock (layers and orientation of the fabric results from its formation), as well as the effective depth and nature of three different types of surface treatments. These treatments were (i) organic and inorganic molecules activating bacteria in the stone, (ii) a conventional stone consolidant and (iii) a biomineralizing protective treatment. The new testing method provided valuable information about the nature of all the three treatments. Therefore the horizontal sorption method (HSM) seems to be a highly promising tool for the analysis of porous materials.
\end{abstract}

Key words: horizontal sorption, rate of water absorption, fabric analysis, migration profile, effective depth of treatment

* Corresponding author; Department of Construction Materials and Engineering Geology, Budapest University of Technology and Economics, Müegyetem rkp. 3. building K, I. 85, H-1111 Budapest, Hungary; Phone: +36-20-238-4064; Fax: +36-1-463-2017; E-mail: juhaszpit@gmail.com

Received: $\quad$ May 13, 2013; accepted: July 15, 2014 


\section{Introduction}

Measurements related to the capillary water absorption characteristics are simple but highly informative means of material analysis. Their relevancy is also very high, since water originates decay of porous stone in a significant number of cases. Water by itself plays an important role in decay: first, by generating pressure against pore walls when it freezes, which results in stone breakdown (Steiger et al. 2011), and second, by filling the pore system through capillary sorption (or rise), which results in the development of additional stresses to the normal load due to non-compressible behavior of water (Török and Vásárhelyi 2010). Water also mediates decay of porous materials due to salt crystallization. Water-soluble salts enter the porous fabric with the water during the capillary absorption process. Upon drying, these salts re-crystallize, and apply pressure to the pore walls. This leads to tension, which causes damage to the stone fabric, decreasing the mechanical resistance of the stone (Steiger et al. 2011). Freezing-thawing and salt crystallization usually occur in cycles, generating repeated tensile stress to the material. Since rigid materials like mortar, concrete and stone have low tensile strength, they can rapidly disintegrate due to these cyclical impacts.

Water absorption measurements give information on the water content, total water uptake and rate of the capillary water absorption of the porous materials (Balázs 2009). Of these measurements, only the rate of the capillary water absorption can be performed in-situ. However, the water content of a structure (e.g. masonry made of stone) can be comparatively measured by a GANN Hydromette (Török 2010), but the measured values cannot be directly converted to mass $(\mathrm{m} / \mathrm{m} \%)$ or volume $(\mathrm{v} / \mathrm{v} \%)$ percentage. Total water content of a structure cannot be measured, since total saturation of the material with water is not possible.

The rate of the capillary absorption of a porous material can be measured in four different ways. These are the capillary rise method, the Karsten pipe method, the contact sponge method and the Mirowski pipe method (Vandevoorde et al. 2009). Of these four methods capillary rise can be measured only under laboratory conditions, according to different national or international standards [e.g. MSZ EN 1925:2000 (E)]. The reason for this is that the measurement requires preparation of samples from the original material. If sampling from the original structure is not possible, the rate of capillary absorption can be measured with the Karsten pipe method, the contact sponge method or with the Mirowski pipe.

The aim of the present paper is to introduce the horizontal sorption method, proposed for the in-situ measurement of the rate of water absorption. Moreover, our aim was to compare this technique to the other, already existing non-destructive methods for measuring water absorption, and to show some special fields of application unique to the horizontal sorption method. The operation of the new technique is explained in comparison with the Karsten pipe and the contact sponge methods. 


\section{Overview of the measuring methods}

\section{Karsten pipe method (KPM)}

The Karsten pipe method consists of a vertical pipe filled with water, which is attached with either plastiline or lime putty to the surface of a porous stone material (Vandevoorde et al. 2009). The round contact area A between the pipe and the stone differs according to the type of the Karsten pipe, but is usually about $5-6 \mathrm{~cm}^{2}$. The rate of the water absorption is calculated from the mass of the absorbed water and the time necessary for the absorption. There are some recommendations on the application of the method, for example the RILEM II.4 recommendation (RILEM 1980). With help of this method the average rate of water absorption is determined in $\mathrm{g} / \mathrm{m}^{2} \mathrm{~s}$. The initial and the final phase of the absorption process are not considered. Water absorption by the stone is determined, for example between 5 and 15 minutes, by measuring the reduction of the water volume in the graduated pipe. The recorded volume values can be converted to the corresponding masses of water, $m_{(5 \mathrm{~min})}$ and $m_{(15 \mathrm{~min})}$. The average water absorption $(k)$ in ten minutes (between 5 and 15 minutes) per unit area can be calculated with Eq. (1). If absorption of the water is very low (materials with low capillary activity, ex. concrete) or too rapid (materials with high capillary activity, e.g. porous limestone), one may choose different time interval:

$$
k=\frac{\Delta m}{A \cdot t}=\frac{m_{(15 \mathrm{~min})}-m_{(5 \mathrm{~min})}}{A \cdot t} .
$$

The advantages of the KPM are that the pipe can be easy attached to the surface under analysis, and the water absorption process can be well documented if the capillary activity of the stone is relatively low. A disadvantage of the Karsten pipe method is that materials with high capillary activity cannot be analyzed. As an example, Pápay and Török (2006) reported that coarse-grained porous limestone soaked the $10 \mathrm{ml}$ of water from the pipe in less than one second, due to its large open pores. Therefore different time intervals (or volume values of the absorbed water) of the measurement should be chosen depending on the type of stone. Another drawback of this testing method is that the pressure of the water is not constant during the measurement. As the height of the water column $\left(h_{(t)}\right)$ decreases in the pipe, the pressure of water $\left(P_{(t)}\right)$ on the absorbing surface decreases according to Eq. (2), where $V_{(t)}$ is the momentary amount of water in the pipe, and $A$ is the cross-section area of the pipe $\left(\mathrm{r}^{2} \cdot \pi\right)$ :

$$
P_{(t)} \sim h_{(t)}=\frac{V_{(t)}}{A} .
$$

Therefore the intensity of the capillary absorption is not constant, but decreases during measurement. As another disadvantage, Vandevoorde et al. (2013) re- 
ported that the KPM suffers further hindrances, namely that the contact area of water and stone is not constant, and the absorption of water begins before the actual start of measurement. Finally, fixation of the pipe onto the stone surface with lime putty will result in non-desired contamination of the surface after detachment of the pipe, due to the residual lime putty.

\section{The contact sponge method (CSM)}

The contact sponge method was developed by Tiano and Pardini (2004), and was used for the determination of water uptake of weathered calcareous stone (Tiano et al. 2006). The method consists of a sponge enclosed in a contact plate. The contact plate is composed of two parts, namely a base and a cover. The diameter of the sponge corresponds with the inner diameter of the base, whereas the height of the sponge exceeds the vertical borders of the base. For the measurement the cover of the contact plate is removed, water is added to the sponge and the sponge (surface area: $23.76 \mathrm{~cm}^{2}$ ) enclosed in the contact plate is weighed $\left(m_{i}\right)$. After weighing, the cover of the contact plate is removed and the sponge is pressed manually against the stone surface until the vertical borders of the base touch the stone surface. After the selected contact time, the contact sponge is removed and weighed inside the closed contact plate $\left(m_{f}\right)$. The water absorption is calculated according to Eq. (1), where A equals the surface of the sponge and $\Delta m$ is calculated as $m_{i}-m_{f}$. The method was further developed by Vandevoorde et al. (2009), who supplemented the sponge with a dynamometric spring. In this way pressure can be applied on the sponge, which accelerates the absorption.

In a comparative test Vandevoorde et al. (2013) showed that the CSM is capable of measuring the initial water uptake of less porous materials with great precision. However, they concluded that the CSM is not suitable for analysis of longer measuring periods and/or of more porous stones, due to the limited amount of water in the sponge. Another disadvantage of the method is that it includes measurement with a balance as well. Because of this action the absorption process will be interrupted. For this reason only few measured points (2-4) will be available for the characterization of the entire absorption process.

\section{Mirowski pipe method (MPM or MIR)}

The Mirowski pipe method was developed and patented by the Polish Prof. Ryszard Mirowski (Patent No. 125504). According to Vandevoorde et al. (2013), the method consists of a graded glass tube, closed at the top and with a small cylindrical body containing a sponge on the other end. For the measurement the pipe is filled with water through the open cylindrical body, after which it is closed by adding the small sponge in the cylindrical body to prevent water from escaping the pipe. The tube is attached to the surface under analysis with a rubber ring with two metal pins, which are fixed to the surface with tape above the designated mea- 
suring point. The filled pipe is then placed in the rubber ring, so that the sponge touches the measuring point. Water is adsorbed by the stone through the sponge by capillary forces. According to the manual of the MIR, the amount of water adsorbed can be recorded by measuring the reduction of the water volume in the graded pipe.

Vandevoorde et al. (2013) reported that the MIR shows too many inconveniences, leading to unreliable results. Among these was the effect of the air entering into the tubes, which was trapped in the sponge in the form of bubbles, instead of rising to the top of the tube and thus lowering the water level during the absorption. As a consequence, the water uptake at a certain contact time could not be recorded correctly (Vandevoorde et al. 2011).

\section{The horizontal sorption method (HSM)}

The horizontal sorption test method (HSM) was developed by Juhász (Juhász and Kopecskó 2012) to overcome some of the disadvantages of the previously detailed measuring methods; namely: (i) the low number of measured points, (ii) materials with high capillary activity cannot be analyzed, (iii) changing water-pressure during the absorption process, (iv) problematic measurement of the initial water absorption and (v) the absorption of water begins before the actual start of the measurement. To achieve this, the following testing protocol was developed.

The testing setup consists of a glass pipette fixed on clips, filled with $5 \mathrm{ml}$ of water, levelled to horizontal position and pressed onto the analyzed point of the surface (perpendicular to the surface) with the pointed end (Fig. 1). For an in-situ measurement the pipette can be fixed onto a stand and levelled. The absorption process is initiated with the plunger of a hypodermic syringe by jointing its outlet to the wider end of the pipette and pressing it. In this way pressure is applied on the water in the pipette for a moment, and when the water reaches the absorbing

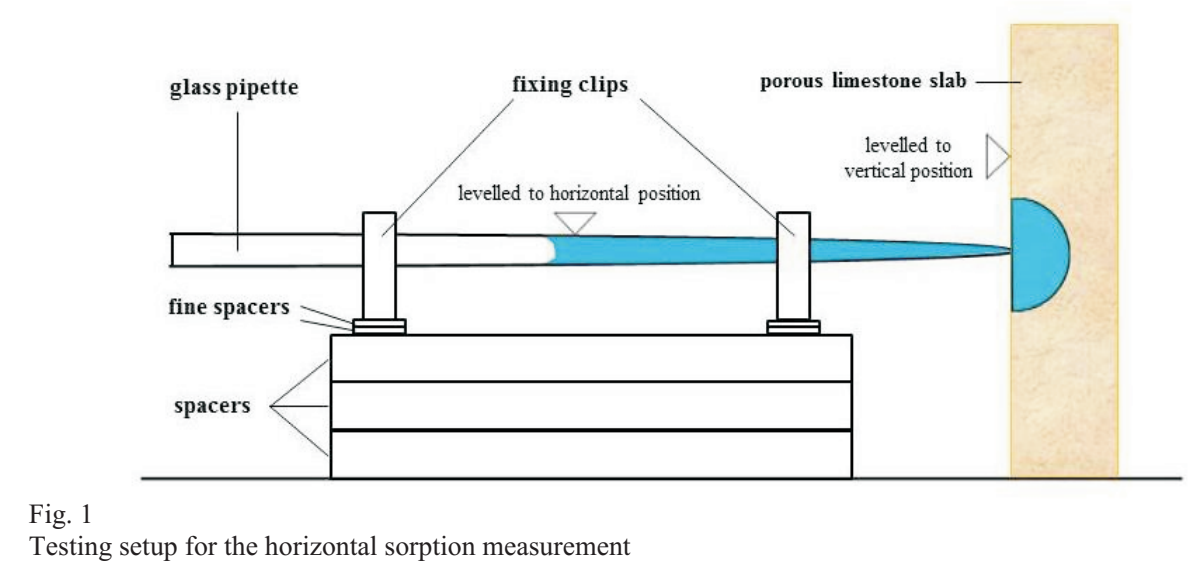


surface, the absorption starts. No further pressure beyond atmospheric pressure is applied on the water during the absorption process.

The glass pipette is scaled (with graduations of $0.05 \mathrm{ml}$ ), and its capacity is 5 $\mathrm{ml}$. The outlet diameter of the pipette is $1 \mathrm{~mm}$; thus the contact area of the water and the analyzed stone surface is only $0.0079 \mathrm{~cm}^{2}$ [compare this to that of the $\mathrm{KPM}\left(5-6 \mathrm{~cm}^{2}\right)$ or that of the CSM $\left.\left(23.76 \mathrm{~cm}^{2}\right)\right]$. The advantage of this small contact area is low water-permeability; thus the pipette is emptied slowly during the absorption. Due to the slow absorption several points (time; volume) can be recorded, and highly capillary active materials can be also analyzed. The inner diameter of the pipette $(6.1 \mathrm{~mm})$ is small enough that surface tension developing between the water and the glass prevents the water from leaking out of the pipette or spread in the pipe. Due to the surface tension the meniscus is clearly visible during the entire absorption process, enabling reading of several measurement points. Since the pipette is in a horizontal position, the pressure of the water is constant during the whole absorption process. Moreover, the initial water absorption can be also measured, since the measurement can be precisely initiated. Finally, the advantage of the HSM is that no fixing material (e.g. plastiline) is needed to develop contact between the measuring tool (the pipette) and the surface under analysis.

\section{Comparison of the different sorption methods}

Vandevoorde et al. (2013) gave a very good comparison of the KPM, CSM and MPM methods from the practical point of view. They reported that limitations in the practical application of the CSM is that it is not suitable for analysis of longer measuring periods and/or of more porous stones, due to the limited amount of water in the sponge, but it is capable of measuring the initial water uptake of less porous materials with high precision. They also stated that "KT (here: KPM) was found incommodious for measurements of the water uptake before 5 minutes, but it has the possibility of measuring longer contact times for more porous stones. MIR showed too many discommodities, leading to unreliable results". Considering the variable factors of the methods, the size of the contact area was found to be "the most decisive parameter influencing the measurements, as pores surrounding the contact area cause an additional sideward adsorption. Differences in contact material did not exhibit a significant influence".

Characteristic of the horizontal sorption method is that the contact area is very small, and the pressure is constant during the absorption process. Therefore longer measuring periods can be also analyzed and measurements can be carried out on more porous stones as well (Juhász et al. 2013). Further fields of application unique to the HSM are shown in this paper. 


\section{Applications of the horizontal sorption method}

\section{Determination of the horizontal capillary absorption coefficient}

The HSM was first applied to quantify the changes in the rate of water absorption of porous limestone samples due to different surface treatments (Juhász et al. 2013). In that experiment bio-based treatments were applied to the surface of porous limestone slabs, and differences in the rate of capillary absorption were studied. Capillary absorption curves obtained before and after the treatment were compared to each other (Fig. 2).

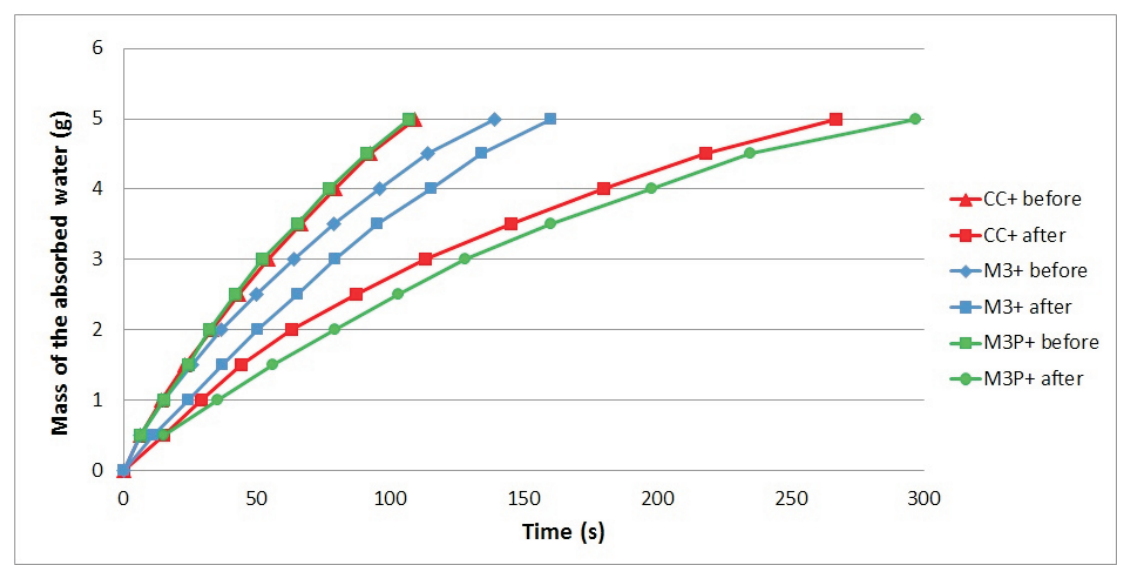

Fig. 2

Capillary absorption curves before and after the different bio-based treatments

If the absorbed amount of water is plotted as a function of the square root of time, the absorption curves will be linear after a certain period of time (Fig. 3). This indicates that after an initial period of time (necessary for the development of continuous absorption) the horizontal sorption will show a similar tendency than during the capillary rise method. In the case of the capillary rise method the absorption curves will be linear as a function of the square root of time (Hohmann et al. 1997). The slope of the linearized curves $\left(s_{b}-\right.$ before the treatment and $s_{a}-$ after the treatment) can be calculated according to Eq. (3):

$$
s=m / \sqrt{t} .
$$

These $s$ values can be converted into a horizontal capillary absorption coefficient according to Eq. (4):

$$
k_{h}=s / A,
$$

where $A$ is the area of the water outlet opening of the pipette. 


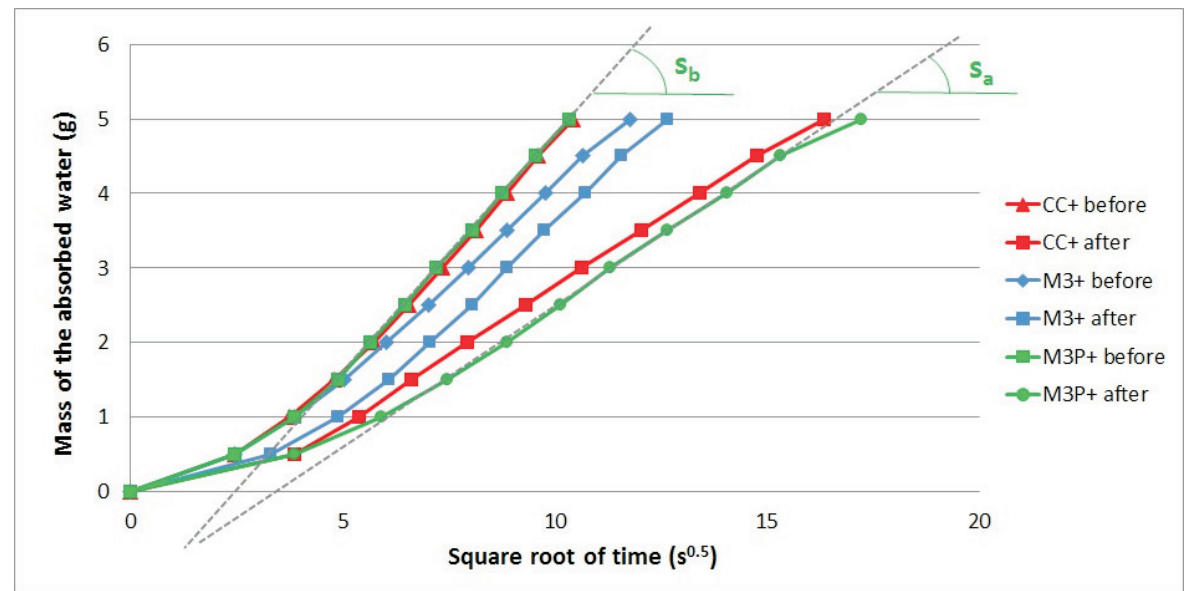

Fig. 3

Linearized capillary absorption curves before and after the different bio-based treatments

The $s$ or $k_{h}$ values are appropriate for the characterization of the entire horizontal capillary absorption process. Unlike the $k$ values calculated by the KPM or the $\mathrm{CSM}$, the $s$ or $k_{h}$ values are based on several measurement points, and they are not only average values measured between two moments of the absorption process. Moreover, the effect of the pores surrounding the contact area causing additional sideward adsorption (Vandevoorde et al. 2009) was shown not to induce error in the measurement.

\section{Determination of the sedimentary fabric of the stone}

Sedimentary rocks usually form in layers, and layering is reflected by the fabric of the rock (Török 2007). These layers give orientation to the fabric, which affects the capillary water absorption properties of the stone. As an example, Pápay and Török (2006) reported that on the same porous limestone samples, twice the absorption time was measured with the KPM perpendicular to the layers than parallel to them. Moreover, Kriston (2000) reported that differences in porosity measured on samples obtained from the same block of building stone may reach $20 \%$, which further modifies the capillary water-absorption properties of the same rock.

The orientation of the fabric of a sedimentary rock is often difficult to detect by naked eye on large stone surfaces. However, if layers are present in the rock, water-absorption will be different in different directions.

The HSM turned out to be an efficient tool for the analysis of the fabric. Since the water contacts the surface on a small point and the absorption process is slow, propagation of the water can be assessed with high accuracy in all the directions on the surface. 
Measurements were carried out on surfaces of intact slabs made of porous limestone from Sóskút. Water began to propagate in all directions around the contact point. Shape of the absorption pattern (the stain) was some sort of even ellipsis in most of the cases. Either circular (Fig. 4a), vertically oriented (Fig. 4b) or horizontal ellipses, as well as uneven shapes (Fig. 4c) were observed. The vertical dimensions of the migration stain measured from the connection point of the pipette downward were only 1-2 millimeters longer than upward. This demonstrates the effect of gravity on the propagation of water. In case of the non-circular shapes, after drying absorption measurements were repeated in a $90^{\circ}$-rotated position of the slabs (landscape) as well. The orientation of the stains was found to be the same as in the previous (portrait) position of the slabs. The orientation of the ellipses (orientation of the longer axis) was considered to be the effect of the layering of the fabric on the water absorption, showing the orientation of the fabric.

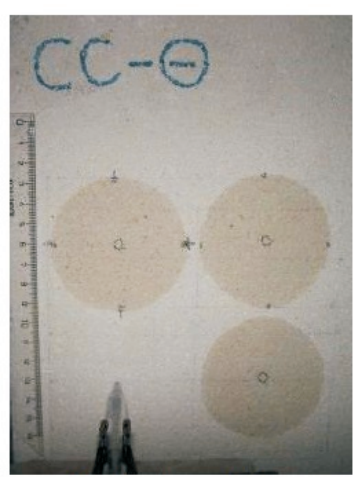

a. Circle-shaped stains

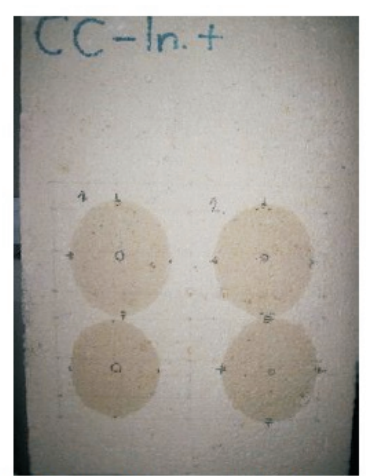

b. Vertically oriented ellipsis-shaped stains

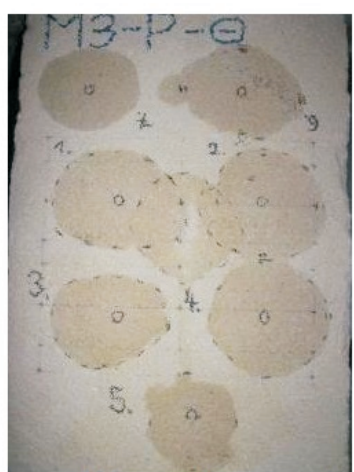

c. Uneven shapes and horizontal ellipses

Fig. 4

Different shapes and orientation of stains on the surface of the slabs

The propagation of water beneath the surface was also analyzed, in a destructive way. For this purpose the absorbed water was preliminarily colored with an appropriate dye which does not separate from the solvent (water) during the absorption due to the filtering effect of the porous stone (this phenomenon is similar to the one used in chromatography). Eventually a naphthol-green solution was used, which was proven to be appropriate for this purpose through preliminary tests performed on pieces of chalk.

First a sample was treated with the naphthol-green solution. After drying it was cut in two through one axis of the spheres (Fig. 5). On the sections the depth of the percolated volume was measured. The depth of migration was found to be equal to the radius of the circle developed on the surface; thus the percolated volume is half-sphere-shaped. This result suggests that if the fabric is not oriented, water will propagate to roughly equal distances from the point of water-inlet in all directions of space. 


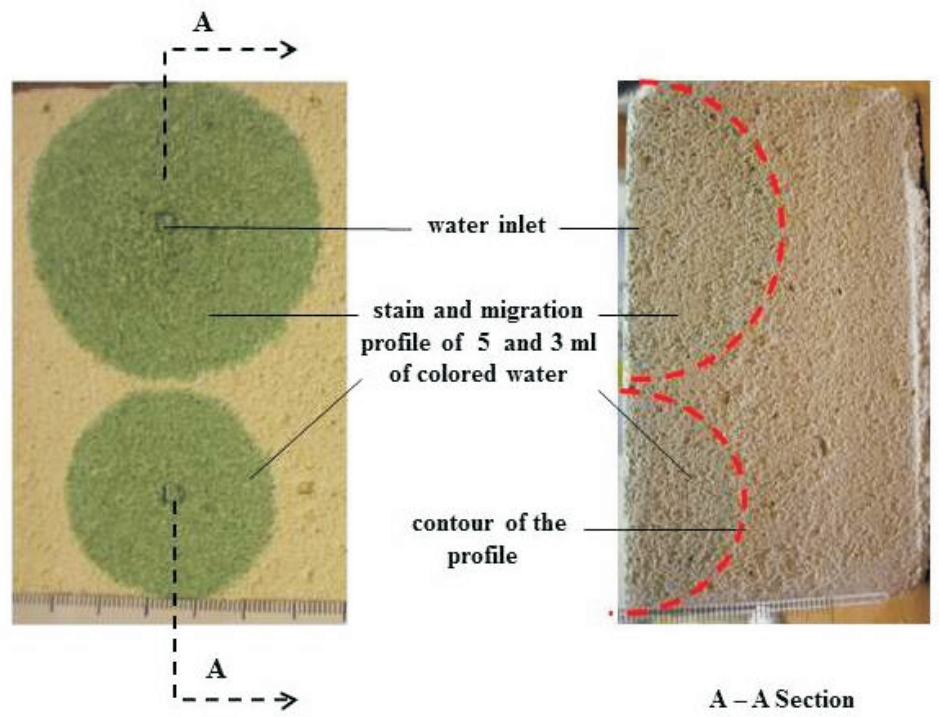

Fig. 5

Shape on the surface and profile in section of the wetted volume

Detection of unattached particles - effect of a bio-inducing surface treatment

The HSM turned out to be an efficient tool for the analysis of the effect of surface treatments as well.

In our experiment one porous limestone (origin: Sóskút, Hungary) slab was prepared, with dimensions of $29.0 \times 19.2 \times 6.4 \mathrm{~cm}$. A bio-inducing surface treatment was applied on the largest surface of this slab in order to activate bacteria inhabiting the stone to produce calcium carbonate crystals. The treatment consisted of repeated application of liquid CB curing compound on the stone surface for four days (Table 1). The liquid compound was made of $25 \mathrm{mg} / \mathrm{ml} \mathrm{BioCa}{ }^{\mathrm{TM}}$ (a product of a French company, made of organic and inorganic molecules) dissolved in distilled water. During the treatment the slab was stored in a room at $26 \pm$ $2{ }^{\circ} \mathrm{C}$ and $50 \pm 5 \%$ relative humidity.

Table 1

Amount of applied curing compound per day

\begin{tabular}{lccccc}
\hline Day & 1 & 2 (p.m.) & 2 (a.m.) & 3 & 4 \\
\hline $\mathrm{V}(\mathrm{ml})$ & 350 & 350 & 175 & 262.5 & 262.5 \\
\hline
\end{tabular}

Horizontal sorption tests were performed on the largest surface of the slab before and one month after the treatment. The measurements were carried out on 
several points of the surface and close to the edge of the slab. Borders of the migration stains were marked with a blue dashed line before, and with a red dashed line after the treatment (Fig. 6).

As result of the treatment the chromatic appearance of the entire slab changed (its beige-burosso color changed to light-yellowish). This shows that the organic and inorganic particles were distributed evenly inside the slab. Wetted areas (size of the stain) and profiles (on the sides - Fig. 6a) were found to be slightly smaller after the treatment. These indicate that as result of the treatment pores of the stone were partly blocked by the accumulated organic and inorganic particles.
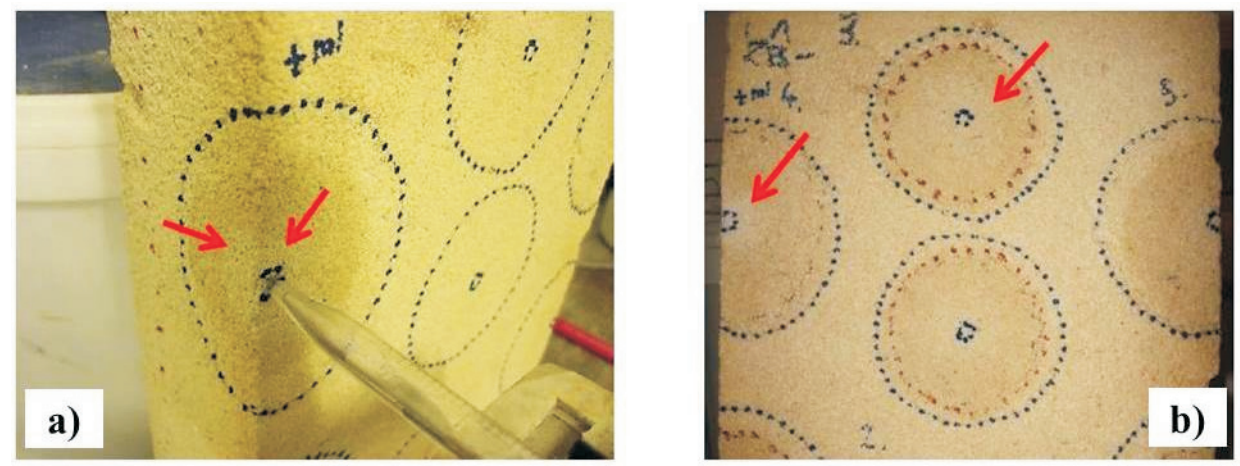

Fig. 6

b) Borders of the wetted areas before (larger, outer circle) and after the treatment (smaller, inner circle). a) and b) Washing out effect around the pointed inlet is visible due to the lighter color of the stone. Margins of the wash-out are marked with arrows

Due to the horizontal sorption tests, light-colored rings appeared around the pointed water-inlet of the pipette. This is due to the "washing effect" of the water migrating into the slab, showing its capacity of "collecting" and pushing forward particles, and eventually accumulating them. This accumulation results in the previously mentioned blocking of the pores and development of the smaller migration profile.

\section{Detection and characterization of a surface layer - effect of a conventional surface treatment}

Young et al. (1999) stated that "water repellents and consolidants are used in an attempt to minimize the rate of stone decay and to strengthen decayed stone where there has been a failure of the natural stone cement through the normal processes of weathering, the effects of atmospheric pollution or through inappropriate intervention". Two important criteria for successful treatments are the adequate penetration depth and that the treatment "should not block the porosity of the stone or significantly reduce the rate of moisture transport through the stone". 
These two criteria were analyzed with the help of the HSM in an experiment where a porous limestone slab was treated with a conventional stone consolidant. $400 \mathrm{ml}$ of acrylic consolidant, a resin-based primer, was mixed together with $100 \mathrm{ml}$ water, and was applied onto the largest side of a porous limestone slab (dimensions: $29.0 \times 19.2 \times 6.4 \mathrm{~cm}$; treated surface area: $556.8 \mathrm{~cm}^{2}$ ) by capillary uptake. The migration depth of the compound was marked on each lateral side of the slab with a red broken line. After drying the migration depth of the consolidant was perceptible by naked eye as a yellowish zone developed on the lateral sides of the slab. The width of this zone was found to be smaller than the migration depth of the water-polymer dispersion (Fig. 7). This indicated that water separated from the liquid consolidant during the sorption and propagated further into the stone. The migration depth of the consolidant was measured to be an average of $26.3 \mathrm{~mm}$ for the dosage of $0.72 \mathrm{ml} / \mathrm{cm}^{2}$. This corresponds to $1464.4 \mathrm{~cm}^{3}$ treated volume. Considering the preliminary measured apparent porosity of this type of porous limestone $(29.2 \pm 1.2 \mathrm{v} / \mathrm{v} \%, \mathrm{n}=10)$, the apparent porosity of the treated volume is about $410.2-445.2 \mathrm{~cm}^{3}$. Since the residual dry matter content of the consolidant was measured to be $18.4 \mathrm{v} / \mathrm{v} \%$, the volume of the dry matter (gel) added to the stone by $400 \mathrm{ml}$ of liquid compound is about $73.6 \mathrm{~cm}^{3}$. This volume is lower than apparent porosity of the treated volume; thus it can concluded that the pores were not totally blocked by the treatment.

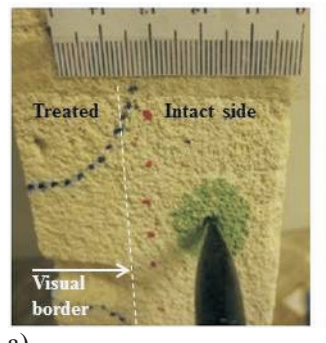

a)

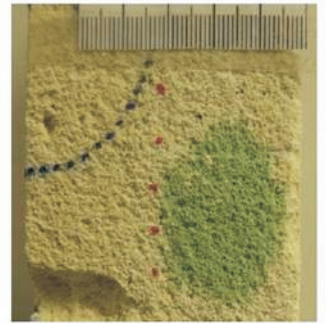

b)

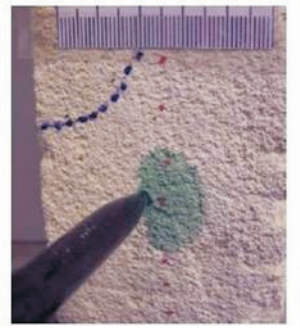

c)

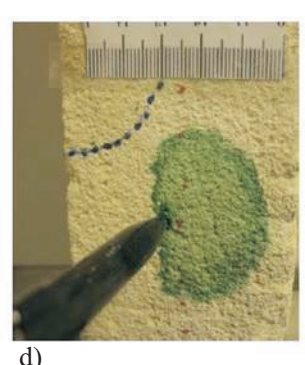

d)

Fig. 7

Development of an even, vertical ellipse outside the migration border at the same spot $a$ (in the beginning) and $b$ (at the equilibrium state); development of an uneven shape due to hindered sorption in the left direction c (in the beginning) and d (later on). The vertical margin of the treatment is clearly visible

However, the horizontal capillary absorption was completely hindered on the surface by the treatment (measured two months after the treatment). Since pores were not blocked, this result suggests that the treatment has a secondary hydrophobizing effect. This was further proved when droplets were poured onto the surface, and they were neither absorbed by the stone nor exuded on the surface. Thus the increase of the interfacial tension between the water - stone interface was proven.

Horizontal sorption was tested on the lateral side of the slab as well (Fig. 7). 
When the pipette was pressed to the intact side, a symmetrical vertical ellipsoid developed, as can be seen in Figs $7 \mathrm{a}$ and $7 \mathrm{~b}$. When the pipette was pressed close to the visual migration border of the consolidant on the intact side, a non-symmetric, half-circle-shaped stain developed (Figs $7 \mathrm{c}$ and d). This showed that migration is hindered in the direction of the treated side of the slab. Moreover the contour of the migration profile of the consolidant was clearly visible on the left side of the pipette (Fig. 7d). Thus the margin of the migration of the treatment perceptible by the naked eye was identical to the one visualized by this staining technique.

It should be noted that dying of the water is not necessary for the measurement when the original color of the material (stone) does not mask the developing migration profile of the water. Without dying the measurement does not cause alteration to the material under analysis.

\section{Detection and characterization of a surface layer-effect of a bio-based surface treatment}

Measurement of the water-absorption properties is a commonly used tool to analyze the effect of bio-based surface treatments. Le Métayer-Lever et al. (1999) performed in-situ Karsten pipe measurements on a bio-treated limestone wall, and measured an increase of the absorption time due to the treatment. Heirman et al. (2003) performed laboratory measurements on bio-treated concrete specimens with standing Karsten pipe, but for mortar the KPM did not appear selective enough to describe the surface quality. Tiano et al. (2006) used the contact sponge method to quantify changes in water absorption due to the application of organic matrix macromolecules inducing biodeposition on the stone surface. A significant decrease in the intensity of water absorption was measured compared to the original state of the marble stone after the treatment.

The HSM was shown to be appropriate for the determination of the horizontal capillary absorption coefficient and for the comparison of water absorption properties on intact and bio-treated surfaces. Moreover, measurements similar to those shown in Figs 5 and 6, performed on bio-treated stone slabs showed that the HSM can be used for the visualization of bio-originated layers as well.

For the analysis two intact porous limestone slabs (origin: Sóskút) were prepared, of the dimensions of $29.0 \times 19.2 \times 6.4 \mathrm{~cm}$. One was used as a control, the other one was treated with Myxococcusxanthus-inoculated M3-P liquid compound (detailed in Rodriguez-Navarro et al. 2003) on a marked area of $225 \mathrm{~cm}^{2}$ $(15 \times 15 \mathrm{~cm})$. The M3-P liquid compound was amended with $10 \mathrm{mg} / \mathrm{ml}$ finelyground limestone powder. The biomineralizing treatment took five days. On Day 1, $200 \mathrm{ml}$ of bacteria-inoculated compound was applied onto the stone surface by pouring it onto the marked surface area from a glass beaker ( 0 hour). On Day 2, the treatment was repeated twice with 200 and $100 \mathrm{ml}$ of non-inoculated treating compounds, at Hours 24 and 36. On Days 3 and 4 (Hours 60 and 84), the stone slab was treated with $150 \mathrm{ml}$ of non-inoculated treating compound. After 
one week the slabs were cut in two through the treated area, and the horizontal sorption test was performed.

The test was performed with naphthol-green colored water, one month after the treatment. The pipette was pressed onto the treated side of the slabs, close to an edge of the slab (Fig. 8). On the control stone a symmetrical sorption profile was observed (Fig. 8a), while on the treated slab a significant rim developed at the edges of the symmetrical ellipsis-shape (Fig. 8b). The development of this rim was continuous during the sorption test, until reaching equilibrium (Fig. 8c-f).

The reason for the development of such a rim is that mass properties changed in a surficial layer of a few millimeters depth, due to the treatment. This layer allows higher propagation velocity for the water than in the intact stone, because of the alteration in the pore size distribution. According to the Washburn equation high initial capillary absorption speed is typical for larger pore size diameter (Szekely et al. 1971); thus the increased overall speed of water absorption can be attributed to the decrease of the proportion of small-sized pores. This can be explained by plugging of micropores by the limestone powder and the newly-formed carbonate crystals, which ended capillary sorption. The migration profile was almost identical upon repeated sorption tests (the stone was dried between the tests) - see the black contour lines in Fig. 8c-f. This indicates that the effect of the treatment is permanent, or at least long-lasting.

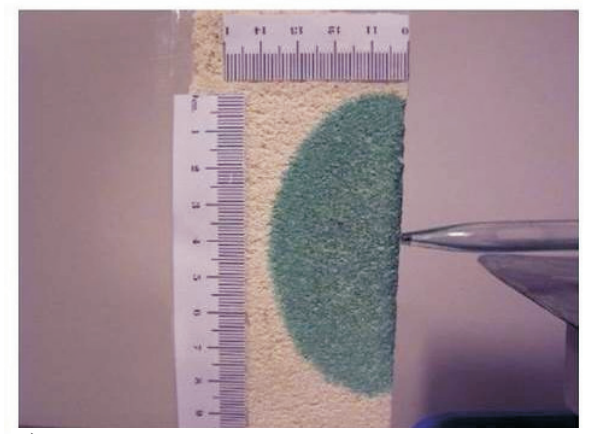

a)

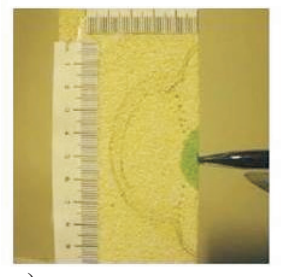

c)

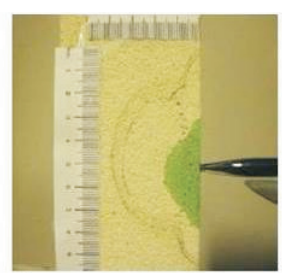

d)

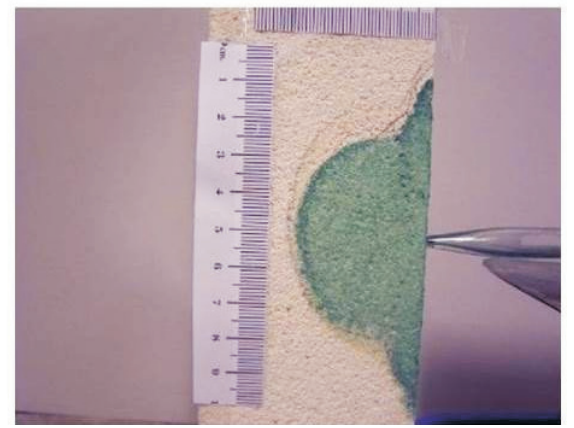

b)

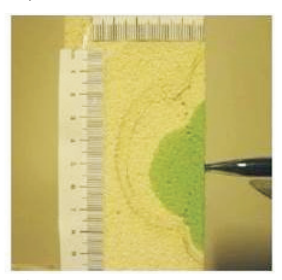

e)

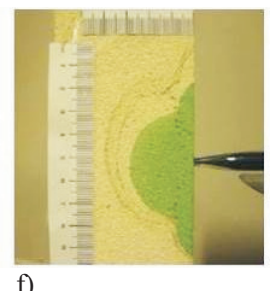

f)

Fig. 8

Profiles of the absorption: a) intact stone, symmetrical, even profile; b) treated stone, symmetrical profile with rim; c) to d) shape of the sorption profile at 5, 11, 24 and 37 minutes 
The penetration depth of the treatment can be estimated by measuring the initial thickness of the rim (Juhász et al. 2013). In the present experiment the effective depth of the treatment was measured to be an average of $4.5 \mathrm{~mm}$.

It should be noted that dying of the water is not necessary for the measurement when the original color of the material (stone) does not mask the developing migration profile of the water. The absence of dying for the measurement does not cause alteration to the material under analysis. However, the migration profile cannot be analyzed in-situ if the lateral side of the element is not accessible without causing damage to the construction.

\section{Conclusions}

In the present paper the horizontal sorption method (HSM) was introduced, and its applicability and relevancy was evaluated in comparison with other testing methods (Karsten pipe, contact sponge, Mirowski pipe).

The horizontal sorption method is shown to be relevant to carry out and quantify in-situ water absorption measurements even in longer periods of time, and also on more porous stone material.

Unique fields of applications of this technique were also shown: (i) detection of the orientation of the fabric and determination of the possible inhomogeneity of the stone material without destructive sampling; (ii) detection of surface treatments applied on the stone and (iii) characterization of the surface layers (hydrophobic nature, capillary absorption characteristic of the layer). These analyses can be also performed with non-dyed water, depending on the color and shade of the stone. In this case the analysis does not cause alteration to the original material.

Eventually, not only water, but other liquid compounds can also be applied to the stone material with help of the horizontal sorption method. Since the quantity of the treating compound can be easily adjusted and controlled, and it is possible to control the treatment from point to point (e.g. a consolidant), small pieces of stone (e.g. a piece of a sculpture) can be also treated by the HSM.

\section{Acknowledgements}

The work reported in the paper was developed in the framework of the project "Talent care and cultivation in the scientific workshops of BME" project. This project is supported by the TÁMOP-4.2.2.B-10/1-2010-0009 grant. The project was also funded by the Pro Progression Foundation.

\section{References}

Balázs, Gy. 2009: Építőanyagok és kémia (Construction materials and chemistry). $6^{\text {th }}$ Edition, Műegyetemi Kiadó, pp. 77-81, p. 655.

Heirman, G., B. De Graef, W. De Windt, T. Herremans, T. Vangheel, D. Van Gemert, N. De Belie, W. Verstraete 2003: Biological Repair of Damaged Concrete and Mortar Surfaces: Biomineralisation. Lirias - KU, Leuven, p. 12. 
Hohmann, R., M. Setzer 1997: Bauphysikalische Formeln und Tabellen (Building physical formulae and tables), $3^{\text {rd }}$ Edition. Werner Verlag, 443 pp.

Juhász, P., K. Kopecskó 2012: Changes of color and water-absorption of Hungarian porous limestone due to biomineralization. - IOP Conference Series: Materials Science and Engineering 47 (2013) Paper012036, pp. $1-7$.

Juhász, P., Á. Suhajda, K. Kopecskó 2013: Analysis of the effective depth of a biominearlizing treatment. In: Józsa, J., T. Lovas, R. Németh: Proceedings of the Second Conference of Junior Researchers in Civil Engineering 2013.

Kriston, L. 2000: A kö- és vakolatrestaurálás alapismeretei (Basic knowledge on the restoration of plasters and stone materials). - Notes for the students of the Hungarian University of Fine Arts, Hungarian University of Fine Arts, Budapest, $125 \mathrm{pp}$.

Le Métayer-Lever, G., S. Castanier, G. Orial, J-F. Loubière, J-P. Perhuisot 1999: Applications of bacterial carbonatogenesis to the protection and regeneration of limestones in buildings and historic patrimony. Sedimentary Geology, 126, pp. 25-34.

Pápay, Z., Á. Török 2006: Durva mészkövek vízfelvételi tulajdonságai (Water absorption properties of porous limestones). - In: Török, Á., B. Vásárhelyi (eds): Mérnökgeológia Kőzetmechanika 2006 (Engineering Geology Rock Mechanics 2006), pp. 197-203.

Reunion Internationale des Laboratoires d'Essais et de Recherches sur les Materiaux et les Constructions (RILEM), Recommandations provisoires de la commission 25-PEM Protection et érosion des monuments. Essais recommandés pour mesurer l'altération des pierres et évaluer l'efficacité des méthodes de traitement. - In: Matériaux de Constructions, vol. 13, No. 75, RILEM, Paris, 1980.

Rodriguez-Navarro, C., M. Rodriguez-Gallego, K. Ben Chekroun, M.T. Gonzalez-Muñoz 2003: Conservation of ornamental stone by Myxococcusxanthus-induced carbonate biomineralization. - Applied Environmental Microbiology, 69, pp. 2182-2193.

Steiger, M., A. Elena Charola, K. Sterflinger 2011: Weathering and deterioration. - In: Siegermund, S., R. Snethlage (eds): Stone in Architecture, Properties, Durability. Springer, Berlin - Heidelberg, pp. 227-316.

Szekely, J., A.W. Neumann, Y.K. Chuang 1971: The rate of capillary penetration and the applicability of the Washburn equation. - Journal of Colloid and Interface Science, 35(2), pp. 273-278.

Tiano, P., C. Pardini 2004: Valutazione in situ deitrattamentiprotettivi per ilmaterialelapideo (In situ validation of protective treatments for stone materials). Proposta di unanuovasemplicemetodologia (Proposition of a new simple method CNR-ICVBC). - Firenze, Arkos 5, gennaio/marzo 2004, pp. 30-36.

Tiano, P., E. Cantisani, I. Sutherland, J.M. Paget 2006: Biomediated reinforcement of weathered calcareous stones. - Journal of Cultural Heritage, 7(1), pp. 49-55.

Török, Á. 2007: Geológia mérnököknek (Geology for engineers). - Mủegyetemi Kiadó, Budapest, 384 pp.

Török, Á. 2010: In situ methods of testing stone monuments and the application of nondestructive physical properties testing in masonry diagnosis. - In: Bostenaru Dan, M., R. Přikryl, Á. Török (eds): Materials, Technologies and Practice in Historic Heritage Structures. Springer, Dordrecht - New York, pp. 177-193.

Török, Á., B. Vásárhelyi 2010: The influence of fabric and water content on selected rock mechanical parameters of travertine, examples from Hungary. - Engineering Geology, 115, pp. 237-245.

Vandevoorde, D., M. Pamplons, O. Schalm, Y. Vanhellemont, V. Cnudde, E. Verhaeven 2009: Contact-sponge method: Performance of a promising tool for measuring initial water absorption. - Journal of Cultural Heritage, 10, pp. 41-47.

Vandevoorde, D., V. Cnudde, J. Dewanckele, M.N. Boone, E. Verhaeven 2011: Contact-sponge method: Performance compared with Capillary Rise, Karsten tube and Mirowski pipe. - In: Proceedings of the EWCHP-2011 Workshop and Training Day, Berlin, 26-28 September 2011, pp. 117-125.

Vandevoorde, D., V. Cnudde, J. Dewanckele, L. Brabant, M. de Bouw, V. Meynen, E. Verhaeven 2013: Validation of in situ applicable measuring techniques for analysis of the water adsorption by stone. - In: Procedia Chemistry, YOuth in the COnservation of CUltural Heritage, YOCOCU 2012, Vol. 8, pp. 317-327.

Young, M.E., M. Murray, P. Cordiner 1999: Stone consolidants and chemical treatments in Scotland. - Report to Historic Scotland, p. 298.

Referred standard:

MSZ EN 1925:2000 (E) Natural stone test methods - Determination of water absorption coefficient by capillarity absorption. 